\title{
microRNA-181a is associated with poor prognosis of colorectal cancer
}

\author{
JUNICHI NISHIMURA ${ }^{1}$, RIO HANDA ${ }^{1}$, HIROFUMI YAMAMOTO ${ }^{1}$, FUMIAKI TANAKA ${ }^{1}$, KOHEI SHIBATA ${ }^{2}$, \\ KOSHI MIMORI ${ }^{2}$, ICHIRO TAKEMASA ${ }^{1}$, TSUNEKAZU MIZUSHIMA ${ }^{1}$, MASATAKA IKEDA $^{1}$, \\ MITSUGU SEKIMOTO $^{1}$, HIDESHI ISHII ${ }^{1}$, YUICHIRO DOKI ${ }^{1}$ and MASAKI MORI ${ }^{1}$ \\ ${ }^{1}$ Department of Gastroenterological Surgery, Graduate School of Medicine, Osaka University, Suita, Osaka 565-0871; \\ ${ }^{2}$ Department of Molecular and Cellular Biology, Division of Molecular and Surgical Oncology, \\ Medical Institute of Bioregulation, Kyushu University, Beppu, Ohita 874-0838, Japan
}

Received June 6, 2012; Accepted August 3, 2012

DOI: $10.3892 /$ or.2012.2059

\begin{abstract}
RNAs regulate gene expression at the post-transcriptional level by degradation of mRNA and translational repression. Recent studies have shown that miR-181a is dysregulated in several types of cancer; however, the clinical significance of miR-181a in colorectal cancer (CRC) remains unclear. We addressed this question by using quantitative real-time PCR (qRT-PCR) to analyze miR-181a expression in $162 \mathrm{CRC}$ patients. There was no significant difference in miR181a expression in normal colon vs. colorectal cancer tissue. The cancer tissue samples were categorized into a low and high expression group based on miR-181a expression. Comparison of the clinicopathological factors and prognosis in these two groups showed that the high expression group had a significantly poorer prognosis than the low expression group $(\mathrm{P}=0.011)$. Multivariate analysis indicated that high miR-181a expression was an independent significant prognostic factor for CRC. However, there no correlation was observed between miR-181a expression and clinicopathological parameters. In vitro analysis revealed that the overexpression of miR-181a repressed the expression of the tumor suppressor, phosphatase and tensin homolog (PTEN) located on chromosome 10, at the mRNA level. These data suggest that miR-181a may be a new independent prognostic factor for CRC patients.
\end{abstract}

\section{Introduction}

Colorectal cancer (CRC) is the second most common cancer in women and the third most common in men in developed

Correspondence to: Dr Hirofumi Yamamoto, Department of Gastroenterological Surgery, Graduate School of Medicine, Osaka University, Yamadaoka 2-2, Suita, Osaka 565-0871, Japan

E-mail: hyamamoto@gesurg.med.osaka-u.ac.jp

Key words: microRNA, colorectal cancer, prognosis, phosphatase and tensin homolog countries (1). Current monoclonal antibody-based therapies have improved the prognosis of CRC patients. These agents include bevacizumab, an inhibitor of the vascular endothelial growth factor (VEGF), and cetuximab, an epidermal growth factor receptor (EGFR) inhibitor. However, long-term survival remains low for metastatic CRC. A better understanding of the molecular mechanisms underlying $\mathrm{CRC}$ is essential for the development of novel therapeutic strategies.

microRNAs (miRNAs) are endogenous single-stranded non-coding RNAs of 19-25 nucleosides in length that are generated by Dicer, an RNase III enzyme. miRNAs regulate gene expression at the post-transcriptional level by the degradation of mRNA and translational repression. miRNAs play essential roles in diverse processes, including development, proliferation, differentiation and apoptosis (2-4). miRNAs function as negative regulators of gene expression, and the overexpression of oncogenic miRNAs can contribute to tumorigenesis by promoting cellular proliferation and evasion of apoptosis.

In CRC, the dysregulation of miRNAs has been reported to influence carcinogenesis, invasion and metastasis. The first study of miRNA expression in CRC in 2003 identified miR-143 and miR-145 as novel dysregulated miRNAs (5). Since then, numerous miRNAs have been reported that are related to $\mathrm{CRC}$ prognosis.

Alternative expression of miR-181a has been reported in a number of cancers. miR-181a is a prognostic marker in acute myeloid leukemia (6) and non-small cell lung cancer (7). The screening of miRNAs implicated in other cancers has shown that miR-181a is upregulated in CRC; however, there has been no assessment of its correlation with clinicopathological and prognostic factors. Since miR-181a has been reported to be overexpressed in TP53 null cells (8), miR-181a may also be involved in the carcinogenesis of CRC.

In the present study, we investigated miR-181a as an oncogenic miRNA in CRC. We demonstrate that miR-181a has clinical significance as a prognostic indicator in CRC. Our data also suggest that the expression of the tumor suppressor protein, phosphatase and tensin homolog (PTEN), may be suppressed by miR-181a, resulting in the suppression of the PTEN/Akt pathway. 


\section{Materials and methods}

Clinical tissue samples. This study included 162 patients who underwent resection of primary CRC at Kyushu University Hospital (Beppu, Japan) or at its affiliated hospitals between 1992 and 2000. Resected tissue samples were immediately cut and embedded in Tissue-Tek OCT compound (Sakura Finetechnical Co., Ltd., Tokyo, Japan), frozen in liquid nitrogen and stored at $-80^{\circ} \mathrm{C}$ until RNA extraction. The clinicopathological factors and clinical stage were classified using the criteria of the International Union Against Cancer (9). All sample data, including age, gender, tumor size and depth, lymph node metastasis, vascular invasion, distant metastasis, clinical stage and histological grade, were obtained from the clinical and pathological records. The mean follow-up period was 35.6 months. None of the patients had pre-operative chemotherapy or irradiation. After surgery, patients with stage III/IV tumors were treated with standard 5-fluorouracil-based chemotherapy. The Human Ethics Review Committee of Osaka University (Osaka, Japan) and Kyusyu University (Ohita, Japan) approved the use of the resected samples. The reporting recommendations for tumor marker prognostic studies (REMARK) guidelines for tumor marker studies were used for the preparation of this study (10).

Evaluation of miR-181a expression in clinical samples. For the quantitative real-time PCR (qRT-PCR) analysis of miR-181a, cDNA was synthesized from 10 ng of total RNA using TaqMan ${ }^{\mathrm{TM}}$ MicroRNA hsa-miR-181a-specific primers (Applied Biosystems, Tokyo, Japan) and the TaqMan ${ }^{\text {TM }}$ MicroRNA Reverse Transcription kit (Applied Biosystems). Reverse transcription conditions were as described previously (11). miRNA expression was determined relatively to the expression of RNU6B (control) and was analyzed using the $\Delta \Delta \mathrm{C}_{\mathrm{t}}$ method (12).

Cell cultures. The Colo 201 colon cancer cell line was maintained in Dulbecco's modified Eagle's medium (DMEM) containing 10\% FBS (Sigma-Aldrich, St. Louis, MO), $100 \mathrm{U} / \mathrm{ml}$ penicillin and $100 \mu \mathrm{g} / \mathrm{ml}$ streptomycin in a humidified atmosphere with $5 \% \mathrm{CO}_{2}$ at $37^{\circ} \mathrm{C}$. Cell count was assessed using a hemocytometer.

Transfection of miR-181a precursor (pre-miR-181a). Cells were grown to $60-80 \%$ confluence and transfected with $5 \mathrm{nmol} / \mathrm{l}$ of pre-miR-181a or negative control oligonucleotides (Applied Biosystems) using the siPORT ${ }^{\mathrm{TM}}$ NeoFX Transfection Agent (Ambion, Inc., Austin, TX). miR-181a expression was analyzed in the cells 24 and $48 \mathrm{~h}$ after transfection, and PTEN expression was analyzed $24 \mathrm{~h}$ after transfection.

Evaluation of PTEN mRNA expression in the Colo 201 cell line. Total RNA was extracted from Colo 201 cells using the modified acid-guanidine-phenol-chloroform method described previously (13). Total RNA ( $8 \mu \mathrm{g}$ ) was reverse-transcribed to cDNA with M-MLV RT (Invitrogen, Carlsbad, CA). The PCR primer sequences for PTEN mRNA were as follows: PTEN forward, 5'-GAGGGATAAAACACCATG-3' and reverse, 5'-AGGGGTAGGATGTGAACCAGTA-3'. Glyceraldehyde-3phosphate dehydrogenase (GAPDH) was used as the internal control, and the GAPDH primers were as follows: GAPDH

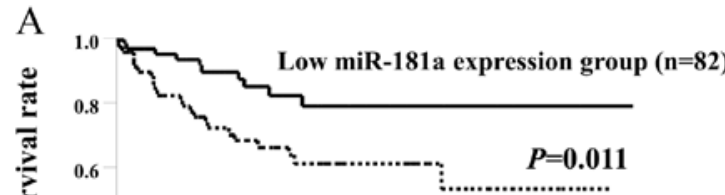

High miR-181a expression group $(n=80)$

ठั)
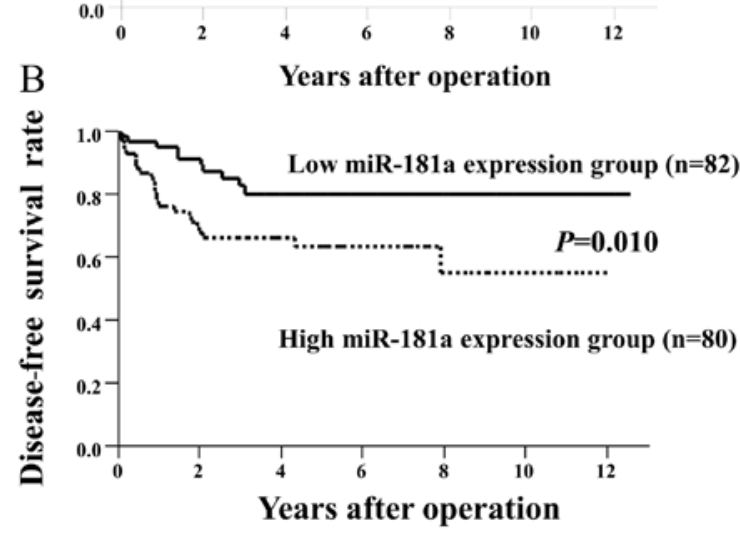

Figure 1. Patients in the high miR-181a expression group had a significantly shorter (A) five-year overall survival rate and (B) disease-free survival rate than those in the low miR-181a expression group ( $\mathrm{P}=0.011$ and 0.010 , respectively).

forward, 5'-TTGGTATCGTGGAAGGACTCTA-3' and reverse, 5'-TGTCATATTTGGCAGGTT-3'. Real-time monitoring of PCR was performed with the LightCycler ${ }^{\circledR}$ system (Roche Applied Science, Indianapolis, IN) and SYBR-Green I dye (Roche Diagnostics, Tokyo, Japan). Monitoring was performed according to the instructions of the manufacturer as described previously (14). In brief, a master mixture was prepared on ice that contained $1 \mu \mathrm{M}$ of cDNA, $2 \mu \mathrm{l}$ of DNA Master SYBRGreen I mix, $50 \mathrm{ng}$ of primers and $24 \mu \mathrm{l}$ of $25 \mathrm{mmol} / 1 \mathrm{MgCl}_{2}$. The final volume was adjusted to $20 \mu 1$ with water. qRT-PCR was performed as described previously (15). The concentrations of unknown samples were calculated by plotting their crossing points against the standard curve and dividing by the value for GAPDH.

Statistical analysis. The qRT-PCR data were analyzed with $\mathrm{JMP}^{\circledR} 8$ (SAS Institute, Cary, NC). The overall survival rates were calculated by the Kaplan-Meier method and were measured starting on the day of surgery. The differences between groups were estimated using the $\chi^{2}$ test, the Student's t-test or the log-rank test. For multivariate analysis, the Cox proportional hazards regression model was used. A probability level (P-value) of 0.05 was used to determine statistically significant diferences.

\section{Results}

Clinicopathological significance of miR-181a expression in $C R C$. In this study, the CRC cases were classified into two groups, a low expression group $(\mathrm{n}=82)$ with miR-181a levels less than the median expression level and a high expression group $(\mathrm{n}=80)$ with miR-181a expression above the median level. We compared overall (Fig. 1A) and disease-free survival (Fig. 1B) 
Table I. miR-181a expression and clinicopathological characteristics in colorectal cancer patients $(n=162)$.

\begin{tabular}{|c|c|c|c|}
\hline Characteristic & $\begin{array}{l}\text { Low expression group }(\mathrm{n}=82) \\
\mathrm{n}(\%)\end{array}$ & $\begin{array}{l}\text { High expression group }(\mathrm{n}=80) \\
\mathrm{n}(\%)\end{array}$ & P-value \\
\hline Age $($ mean \pm SD) & $67.0 \pm 1.20$ & $66.7 \pm 1.21$ & 0.83 \\
\hline \multicolumn{4}{|l|}{ Gender } \\
\hline Male & $48(58.6)$ & $50(62.5)$ & \multirow[t]{2}{*}{0.61} \\
\hline Female & $34(41.4)$ & $30(37.5)$ & \\
\hline \multicolumn{4}{|l|}{ Histological grade } \\
\hline Well and moderately differentiated & 77 (93.9) & $72(90.0)$ & \multirow[t]{2}{*}{0.36} \\
\hline Poorly differentiated and other grades & $5(6.1)$ & $8(10.0)$ & \\
\hline \multicolumn{4}{|l|}{ Size $(\mathrm{mm})$} \\
\hline$<33$ (small) & $13(17.1)$ & $19(23.7)$ & \multirow[t]{2}{*}{0.3} \\
\hline$>31$ (large) & $63(82.9)$ & $61(76.3)$ & \\
\hline \multicolumn{4}{|l|}{ Tumor depth ${ }^{\mathrm{a}}$} \\
\hline $\mathrm{m} / \mathrm{sm}$ & $9(11.0)$ & $12(15.0)$ & \multirow[t]{2}{*}{0.45} \\
\hline $\mathrm{mp} / \mathrm{ss} / \mathrm{se} / \mathrm{si}$ & $73(89.0)$ & $68(85.0)$ & \\
\hline \multicolumn{4}{|l|}{ Lymph node metastasis } \\
\hline Absent & $45(54.9)$ & $45(56.3)$ & \multirow[t]{2}{*}{0.86} \\
\hline Present & $37(45.1)$ & $35(43.7)$ & \\
\hline \multicolumn{4}{|l|}{ Lymphatic invasion } \\
\hline Absent & $48(58.5)$ & $43(53.8)$ & \multirow[t]{2}{*}{0.54} \\
\hline Present & $34(41.5)$ & $37(46.2)$ & \\
\hline \multicolumn{4}{|l|}{ Venous invasion } \\
\hline Absent & $65(79.3)$ & $66(82.5)$ & \multirow[t]{2}{*}{0.6} \\
\hline Present & $17(20.7)$ & $14(17.5)$ & \\
\hline \multicolumn{4}{|l|}{ Liver metastasis } \\
\hline Absent & $72(87.8)$ & $68(85.0)$ & \multirow[t]{2}{*}{0.6} \\
\hline Present & $10(12.2)$ & $12(15.0)$ & \\
\hline \multicolumn{4}{|l|}{ Peritoneal dissemination } \\
\hline Absent & $79(96.3)$ & $77(96.3)$ & \multirow[t]{2}{*}{0.98} \\
\hline Present & $3(3.7)$ & $3(3.7)$ & \\
\hline \multicolumn{4}{|l|}{ Srage } \\
\hline $0-\mathrm{I}$ & $18(22.0)$ & $23(28.8)$ & \multirow[t]{2}{*}{0.32} \\
\hline III-IV & $64(78.0)$ & $57(71.2)$ & \\
\hline
\end{tabular}

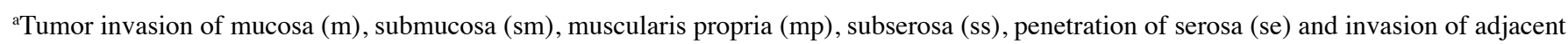
structures (si).

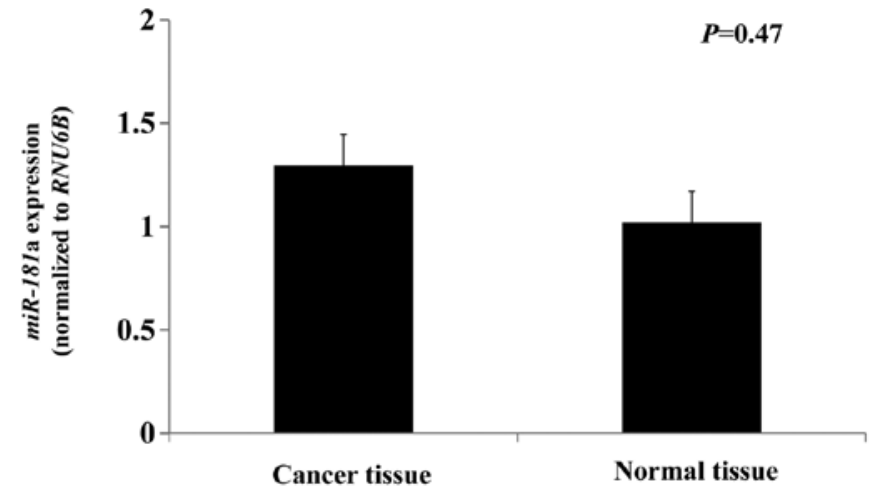

Figure 2. There was no significant difference in the miR-181a expression measured in normal and colon cancer tissue $(\mathrm{P}=0.47)$. between the groups. Patients in the high expression group had significantly poorer prognosis than those in the low expression group (overall survival, $\mathrm{P}=0.011$; disease-free survival, $\mathrm{P}=0.010)$. We also compared miR-181a expression in normal colon mucosa and CRC tissues and found no significant difference (Fig. 2). We then analyzed clinicopathological factors and miR-181a expression. There were no significant differences related to miR-181a expression as regards age, gender, histological grade, tumor size, tumor depth, lymph node metastasis, lymphatic invasion, venous invasion, liver metastasis, peritoneal metastasis or stage (Table I).

Upregulated expression of miR-181a is associated with overall survival. Univariate analysis for overall survival showed that 
Table II. Univariate and multivariate analyses of overall survival in colorectal cancer patients $(\mathrm{n}=162)$.

\begin{tabular}{|c|c|c|c|c|c|c|}
\hline \multirow[b]{2}{*}{ Characteristic } & \multicolumn{3}{|c|}{ Univariate analysis } & \multicolumn{3}{|c|}{ Multivariate analysis } \\
\hline & $\mathrm{RR}$ & $95 \% \mathrm{CI}$ & P-value & RR & $95 \% \mathrm{CI}$ & P-value \\
\hline Age $(>65 /<64$ years $)$ & 0.88 & $0.63-1.26$ & 0.485 & - & - & - \\
\hline Gender (female/male) & 0.91 & $0.63-1.27$ & 0.579 & - & - & - \\
\hline miR-181a expression (high/low) & 1.59 & $1.11-2.35$ & 0.0102 & 1.83 & $1.26-2.76$ & 0.0013 \\
\hline $\begin{array}{l}\text { Histological grade (poorly differentiated and other } \\
\text { grades/well and moderately differentiated) }\end{array}$ & 2.38 & $1.44-3.61$ & 0.0016 & 2.06 & $1.18-3.41$ & 0.0133 \\
\hline Tumor size $(>31 /<30 \mathrm{~mm})$ & 2.37 & $1.30-5.89$ & 0.0022 & 1.3 & $0.67-3.31$ & 0.4804 \\
\hline Lymph node metastasis (positive/negative) & 2.81 & $1.87-4.60$ & $<0.0001$ & 1.62 & $1.02-2.79$ & 0.0427 \\
\hline Lymphatic invasion (positive/negative) & 2.18 & $1.52-3.23$ & $<0.0001$ & 1.91 & $1.24-3.04$ & 0.0033 \\
\hline Venous invasion (positive/negative) & 2.1 & $1.47-2.95$ & 0.0001 & 1.85 & $1.25-2.73$ & 0.0025 \\
\hline Liver metastasis (positive/negative) & 2.65 & $1.86-3.73$ & $<0.0001$ & 2.48 & $1.65-3.74$ & $<0.0001$ \\
\hline
\end{tabular}

RR, relative risk.
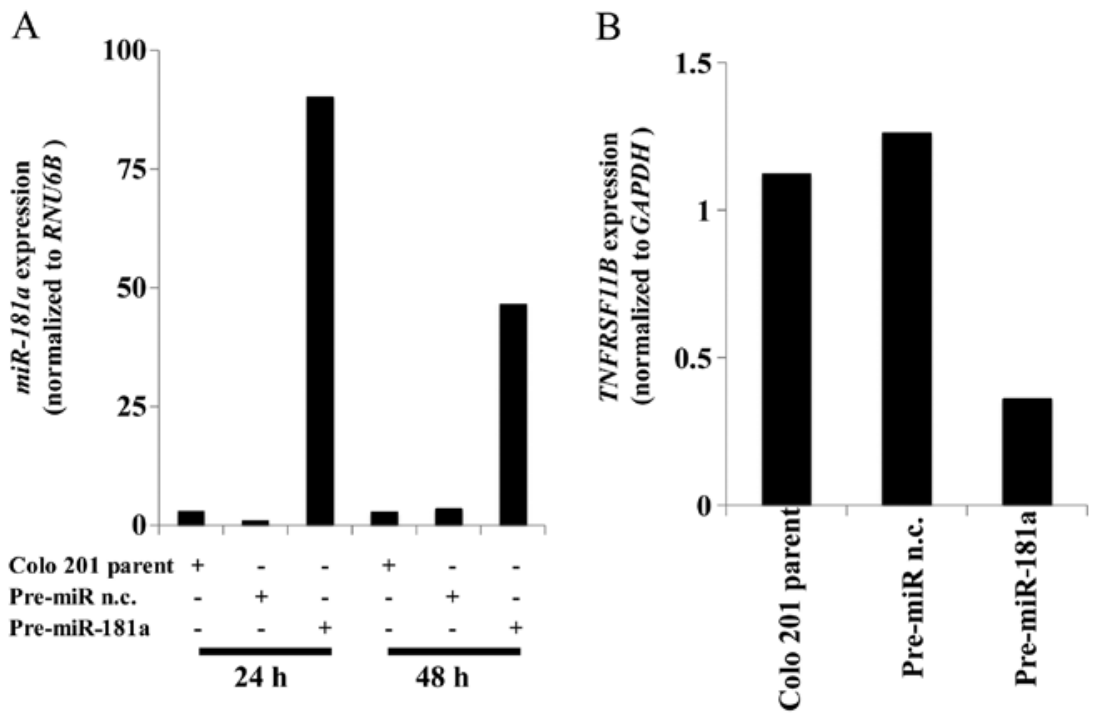

Figure 3. (A) miR-181a expression was analyzed in Colo 201 cells after transfection with pre-miR-181a or the negative control construct. miR-181a expression was low in the pre-miR-181a group at 24 and $48 \mathrm{~h}$. (B) PTEN expression was measured in Colo 201 cells $24 \mathrm{~h}$ after transfection.

several clinicopathological factors, including histological grade, tumor size, lymph node metastasis, lymphatic invasion, venous invasion and liver metastasis, and miR-181a expression, were significant predictors of poor prognosis (Table II). Multivariate analysis showed that miR-181a expression was an independent and significant prognostic factor for overall survival (relative risk, 1.83; 95\% CI, 1.26-2.76; $\mathrm{P}=0.0013$ ); histological grade, lymph node metastasis, lymphatic invasion, venous invasion and liver metastasis were independent and significant prognostic indicators as well (Table II).

miR-181a regulates PTEN expression. We then examined which genes were controlled by miR-181a expression in vitro. Using the in silico miRNA target prediction tools, miRanda and TargetScan, we discovered the sequences of the miR-181a binding sites in transcripts encoding PTEN. To investigate this further, we analyzed miR-181a expression in several colon cancer cell lines. qRT-PCR analysis showed that miR-181a expression in Colo 201 cell lines was lower than other cell lines (data not shown). We then transfected pre-miR-181a into Colo 201 cells and analyzed miR-181a expression using qRT-PCR. miR-181a levels were significantly higher 24 and $48 \mathrm{~h}$ in the transfected cells than in the cells treated with a pre-miR negative control construct (Fig. 3A). The expression levels of PTEN were significantly suppressed in the cells that overexpressed miR-181a (Fig. 3B).

\section{Discussion}

The resutls from the present study showed that miR-181a expression was an independent significant prognostic factor in 
CRC. miR-181a expression did not correlate with clinicopathological parameters, some of which were prognostic factors. These data suggest that miR-181a can affect prognosis via unknown mechanisms. Additional experiments showed that PTEN was a candidate target gene of miR-181a.

miR-181a has been shown to be upregulated in thyroid cancer $(16,17)$ and non-small cell lung cancer (7) and downregulated in glioma cells (18). Kanaan et al (19) reported that miR-181a is upregulated during the progression from non-neoplasia to dysplasia in inflammatory bowel diseaseassociated CRC, whereas miR-181a expression decreases when dysplasia develops into cancer. In the present study, we found no differences in miR-181a expression in normal and cancer tissue. Xi et al (8) used miRNA expression array analysis to compare HCT-116 and null-p53 HCT-116 cells and found that miR-181a was controlled in part by the $p 53$ gene. These findings show that miR-181a may be related to the carcinogenesis of CRC. However, the upstream regulators of miR-181a expression remain unknown. In this study, we analyzed miR-181a expression and prognosis in CRC and found that miR-181a upregulation correlated with worse prognosis. miR-181a expression was not associated with clinicopathological factors. Although miR-181a expression could not be used as a detection marker for CRC, miR-181a might be a new independent prognostic factor in CRC patients.

The reported target genes of miR-181a in acute myeloid leukemia are HOXA7, HOXA9, HOXA11 and PBX3 (20). Pekarsky et al (21) suggested that T cell leukemia/lymphoma 1 (TCL1) expression in chronic lymphocytic leukemia is regulated, at least in part, by miR-181a and that miR-181a may be used as a therapeutic target. In the present study, we detected a different candidate target gene for miR-181a in CRC, namely, PTEN. Since miR-181a expression wadids not correlate with clinicopathological parameters, miR-181a may influence the malignant potential of CRC by controlling PTEN expression.

PTEN is a key tumor suppressor gene, and the loss of PTEN gene expression has been implicated in the carcinogenesis of numerous types of cancer. Specifically, the loss of PTEN expression has been linked to a poorer prognosis in gliomas (22), endometrial carcinomas (23), prostate carcinomas (24), gastric carcinomas (25), as well as CRC (26). Furthermore, PTEN plays a critical role in apoptosis, cell cycle arrest, cell migration and cell spreading (27). The subcellular localization of PTEN has been related to tumor progression, and it is thought that nuclear PTEN regulates cell cycle arrest while cytoplasmic PTEN regulates apoptosis (28). Therefore, miR-181a, which may control PTEN expression, may be a therapeutic target in CRC.

In conclusion, our results show that miR-181a expression does not correlate with clinicopathological characteristics. However, the data suggest that miR-181a expression may be a useful prognostic marker in CRC patients. Further studies are required to investigate the potential of miR-181a as a therapeutic target in CRC.

\section{Acknowledgements}

This study was supported by a Grant-in-Aid for Cancer Research from the Ministry of Education, Culture, Science, Sports and Technology of Japan.

\section{References}

1. Jemal A, Bray F, Center MM, Ferlay J, Ward E and Forman D: Global cancer statistics. CA Cancer J Clin 61: 69-90, 2011.

2. Brennecke J, Hipfner DR, Stark A, Russell RB and Cohen SM: bantam encodes a developmentally regulated microRNA that controls cell proliferation and regulates the proapoptotic gene hid in Drosophila. Cell 113: 25-36, 2003.

3. Lee RC, Feinbaum RL and Ambros V: The C.elegans heterochronic gene lin-4 encodes small RNAs with antisense complementarity to lin-14. Cell 75: 843-854, 1993.

4. Reinhart BJ, Slack FJ, Basson M, et al: The 21-nucleotide let-7 RNA regulates developmental timing in Caenorhabditis elegans. Nature 403: 901-906, 2000.

5. Michael MZ, SM OC, van Holst Pellekaan NG, Young GP and James RJ: Reduced accumulation of specific microRNAs in colorectal neoplasia. Mol Cancer Res 1: 882-891, 2003.

6. Schwind S, Maharry K, Radmacher MD, et al: Prognostic significance of expression of a single microRNA, miR-181a, in cytogenetically normal acute myeloid leukemia: a Cancer and Leukemia Group B study. J Clin Oncol 28: 5257-5264, 2010.

7. Gao W, Yu Y, Cao H, et al: Deregulated expression of miR-21, miR-143 and miR-181a in non small cell lung cancer is related to clinicopathologic characteristics or patient prognosis. Biomed Pharmacother 64: 399-408, 2010.

8. Xi Y, Shalgi R, Fodstad O, Pilpel Y and Ju J: Differentially regulated micro-RNAs and actively translated messenger RNA transcripts by tumor suppressor 553 in colon cancer. Clin Cancer Res 12: 2014-2024, 2006.

9. Sobin LH and Fleming ID: TNM Classification of Malignant Tumors, fifth edition (1997). Union Internationale Contre le Cancer and the American Joint Committee on Cancer. Cancer 80: 1803-1804, 1997.

10. McShane LM, Altman DG, Sauerbrei W, et al: REporting recommendations for tumour MARKer prognostic studies (REMARK). Br J Cancer 93: 387-391, 2005.

11. Nishida N, Yamashita S, Mimori K, et al: MicroRNA-10b is a prognostic indicator in colorectal cancer and confers resistance to the chemotherapeutic agent 5-fluorouracil in colorectal cancer cells. Ann Surg Oncol: Feb 10, 2012 (Epub ahead of print).

12. Livak KJ and Schmittgen TD: Analysis of relative gene expression data using real-time quantitative PCR and the 2(-Delta Delta C(T)) method. Methods 25: 402-408, 2001.

13. Mori M, Mimori K, Yoshikawa Y, et al: Analysis of the geneexpression profile regarding the progression of human gastric carcinoma. Surgery 131: S39-S47, 2002.

14. Ogawa K, Utsunomiya T, Mimori K, et al: Clinical significance of human kallikrein gene 6 messenger RNA expression in colorectal cancer. Clin Cancer Res 11: 2889-2893, 2005.

15. Yamamoto H, Kondo M, Nakamori S, et al: JTE-522, a cyclooxygenase-2 inhibitor, is an effective chemopreventive agent against rat experimental liver fibrosis1. Gastroenterology 125: 556-571, 2003.

16. He $\mathrm{H}$, Jazdzewski $\mathrm{K}, \mathrm{Li} \mathrm{W}$, et al: The role of microRNA genes in papillary thyroid carcinoma. Proc Natl Acad Sci USA 102: 19075-19080, 2005.

17. Pallante P, Visone R, Ferracin M, et al: MicroRNA deregulation in human thyroid papillary carcinomas. Endocr Relat Cancer 13: 497-508, 2006.

18. Shi L, Cheng Z, Zhang J, et al: hsa-mir-181a and hsa-mir-181b function as tumor suppressors in human glioma cells. Brain Res 1236: 185-193, 2008.

19. Kanaan Z, Rai SN, Eichenberger MR, et al: Differential microRNA expression tracks neoplastic progression in inflammatory bowel disease-associated colorectal cancer. Hum Mutat 33: 551-560, 2012.

20. Li Z, Huang H, Li Y, et al: Up-regulation of a HOXA-PBX3 homeobox-gene signature following down-regulation of miR-181 is associated with adverse prognosis in patients with cytogenetically-abnormal AML. Blood 119: 2314-2324, 2012.

21. Pekarsky Y, Santanam U, Cimmino A, et al: Tcl1 expression in chronic lymphocytic leukemia is regulated by miR-29 and miR-181. Cancer Res 66: 11590-11593, 2006.

22. Kondo Y, Hollingsworth EF and Kondo S: Molecular targeting for malignant gliomas (Review). Int J Oncol 24: 1101-1109, 2004.

23. Xu B, Yao Q and Dai SZ: Detection of mutation and protein expression of PTEN gene in endometrial carcinoma. Ai Zheng 23: 69-73, 2004 (In Chinese). 
24. Koksal IT, Dirice E, Yasar D, et al: The assessment of PTEN tumor suppressor gene in combination with Gleason scoring and serum PSA to evaluate progression of prostate carcinoma. Urol Oncol 22: 307-312, 2004.

25. Zheng HC, Sun JM, Li XH, Yang XF, Zhang YC and Xin Y: Role of PTEN and MMP-7 expression in growth, invasion, metastasis and angiogenesis of gastric carcinoma. Pathol Int 53: 659-666, 2003.

26. Goel A, Arnold CN, Niedzwiecki D, et al: Frequent inactivation of PTEN by promoter hypermethylation in microsatellite instability-high sporadic colorectal cancers. Cancer Res 64: 3014-3021, 2004.
27. Weng L, Brown J and Eng C: PTEN induces apoptosis and cell cycle arrest through phosphoinositol-3-kinase/Akt-dependent and -independent pathways. Hum Mol Genet 10: 237-242, 2001.

28. Chung JH and Eng C: Nuclear-cytoplasmic partitioning of phosphatase and tensin homologue deleted on chromosome 10 (PTEN) differentially regulates the cell cycle and apoptosis. Cancer Res 65: 8096-8100, 2005. 